\title{
DOSTOIEVSKI EN BAJTÍN: RAÍCES Y LÍMITES DE LA POLIFONÍA
}

IVÁN IGARTUA UGARTE

Universidad del País Vasco

\section{RESUMEN}

El estudio de la obra de Dostoievski ocupa un espacio determinante en la labor investigadora y teorizadora de Mijaíl Bajtín. Algunas de sus más importantes generalizaciones acerca de la novela parten de las conclusiones derivadas del examen del género en Dostoievski. Las innovaciones estéticas que Bajtín le atribuye son en buena medida, sin embargo, descubrimientos compartidos, producto de una especie de coautoría entre el escritor y el crítico, cuyo pensamiento incide en el material literario de Dostoievski. El concepto esencial de la visión bajtiniana de aquél es la polifonía, entendida como el grado supremo del dialogismo y convertida máa tarde - aunque no directamente por Bajtín- en rasgo definitorio de la novela. Pero así como la construcción polifónica de la novela dostoievskiana posee claros antecedentes históricos, el límite conceptual entre el principio dialógico y la polifonía no acaba de ser, en cambio, completamente diáfano. Entre el origen y las posibles fronteras de la polifonía oscilan las observaciones centrales del presente trabajo.

1. El análisis de la obra dostoievskiana que Mijail Bajtín lleva a cabo desde los inicios de su labor como investigador de la literatura -los Problemas de la obra de Dostoievski (1929) se gestaron a comienzos de los años veinteanima gran parte de los aspectos que conforman su teoría general del discurso 
y de la novela, hasta el punto de que algunas de las observaciones del autor acerca del género en cuestión pueden considerarse extensiones más o menos directas de los resultados que arroja el estudio de la narrativa de Dostoievski. El valor de estas investigaciones para su concepción global de la novela en tanto género literario nítidamente contrapuesto al conjunto de todos los demás se hace evidente en cuanto se confrontan las características estructurales que Bajtín atribuye a la novela de Dostoievski con las definiciones con que poco después — cfr. por ejemplo «La palabra en la novela» (1934-35) o «Epopeya y novela» (1941)- determina la naturaleza del género novelístico. Tz. Todorov ha podido afirmar que la tarea teórica y descriptiva que desarrolla Bajtín a partir de ese momento constituye la aplicación y la interpretación de la lección de Dostoievski (Todorov, 1981: 165, cfr. también Herrero Cecilia, 1992: 60). La correlación existente entre las diversas concepciones de Bajtín en los campos filosófico, lingüístico y antropológico viene dada por la idéntica supeditación de todas ellas al principio dialógico que impregna su pensamiento todo, principio que se manifiesta y explicita de forma prácticamente simultánea en aquellos ámbitos de investigación cultural a los que se dedicó Bajtín. De esta manera, tanto las relaciones yo-otro -esquematizadas y enumeradas posteriormente en "Apuntes 1970-1971" ' - como la interacción y mutua confrontación de la palabra (discurso) ajena y la propia, o las reflexiones sobre la esencia del diálogo entre sujetos (diálogo abierto e inacabado como definición de la vida del hombre y de la cultura, cfr. «K pererabotke knigi o Dostoievskom» [«Para una reelaboración del libro sobre Dostoievski»], Bajtín, 1979: 318) aparecen como las distintas ramificaciones - claramente relacionadas entre síde un núcleo de pensamiento presente ya sin lugar a dudas en la redacción del primer Dostoievski.

2. En 1929, a los anteriores estudios, profundamente influyentes, de B. M. Engelhardt (1924) y L. P. Grossman (1925) sobre la obra de Dostoievski viene a sumarse la contribución peculiar —en clave musical, en cierto modode Mijaíl Bajtín, quien por vez primera aplica conceptos como el contrapunto y la polifonía a la prosa del autor de Crimen y castigo ${ }^{2}$. Lo esencial y a la vez lo más novedoso de su aportación se enfrenta al tipo de acercamiento teórico

' Cfr. BAJTiN, 1979: 342-343. All distingue las relaciones entre objetos, las relaciones entre objetos y sujetos, y las relaciones entre sujetos. Este último tipo constituye el dominio de la interacción de conciencias autónomas, donde son posibles las relaciones dialógicas: en él el sujeto se define por su naturaleza concreta (posesión de un nombre propio), su integridad, pero también por su inagotabilidad y su imperfección (entendida como inconclusión).

2 Un ańlisis de la terminologia musical aplicada por Bajtín al discurso de la novela de Dostoievski se ofrece en WALL, 1984: 65-74. Wall discute, inter alia, la pertinencia y las desviaciones 
-que él llamará monológico- de todos los estudios precedentes, según los cuales Dostoievski, sea de una forma o de otra, y pese al aparente caos de ideas y principios de organización del discurso que impera en sus obras, cifra en ellas un determinado mensaje - siempre uno, unitario y globalizante- que el crítico ha de desentrañar. A juicio de Bajtín, lo que hace Dostoievski es, por el contrario, presentar una situación plural por definición, donde las distintas voces o puntos de vista de la novela ni son vehículos de la verdad ni se subordinan a una idea conceptualmente dominante que pudiera estar encarnada en la voz del autor. El diálogo en sus novelas se establece de forma múltiple entre voces ideológicas - la novela de Dostoievski es ante todo novela ideológica (Engelhardt, 1924)- autónomas, situadas en igualdad de condiciones entre sí y con respecto a la voz del autor, lo que supone la negación de una especie de principio de autoridad ideologica presente en las novelas realistas anteriores. En la esfera del lenguaje y de la cultura, una circunstancia estructuralmente idéntica se produce en el plurilingüismo social que aglutina a lenguajes diversos entre los que se establece a su vez un diálogo que los ilumina mutuamente (cfr. «La palabra en la novela») ${ }^{3}$. A esta configuración esencialmente dialógica de las relaciones entre las distintas voces presentes en la novela de Dostoievski Bajtín la denomina polifonía. Cada voz halla su contrapunto (y se identifica por tanto a sí misma) en la presencia de otra voz. La independencia de cada voz o punto de vista, la ausencia de jerarquías entre voces (principio que es respetado por la propia voz del autor) hacen lógicamente imposible el concepto de verdad absoluta, carencia que se expresa en cuanto a la forma en la inconclusión o apertura de la novela de Dostoievski (interpretación relativista que a pesar de ser negada por su propio autor conduce por la vía de la extrapolación que tan asiduamente practicaba Bajtín a la concepción de la vida como diálogo inconcluso, incluso interminable, y por lo tanto abierto, cfr. Bajtín, 1979: 318 y Bajtín, 1994: 193). En el desarrollo de la concepción bajtiniana aquí sí hay un punto de contraste con respecto a trabajos realizados anteriormente, en concreto «El autor y el héroe en la actividad estética (1920-24)». Así como en este trabajo Bajtín diserta en torno a la verdad absoluta y la divinidad del artista, afirmando la superioridad, derivada de la exotopía (traducción todoroviana de vnenajodimost'), del creador con respecto a lo creado, lo que conduce al investiga-

-desde la perspectiva musical_- del término polifonía en tanto concepto referido a la multiplicidad de voces en el discurso narrativo.

${ }^{3}$ Cfr. también LotmaN, 1992: 142-145: $*$ La cultura es en principio políglota, y sus textos siempre se realizan como minimo en el ámbito de dos sistemas semióticos... El texto es heterogéneo y heteroestructural, constituye la manifestación simultánea de diversas lenguas* (Las traducciones de textos originales rusos son, a menos que se indique lo contrario, mías). 
dor a descubrir, en un primera aproximación teórica, el carácter anómalo del discurso de la prosa de Dostoievski (cfr. Todorov, 1979: 506-507), en Problemas de la obra de Dostoievski (1929) se analiza y elogia precisamente lo opuesto, la renuncia artística a lo absoluto, materializada en la multiplicidad de puntos de vista autónomos (plurivocidad) que conducen a la polifonía ${ }^{4}$. Una polifonía narrativa que resulta, según Bajtín (1994: 276), de «la recreación artística de la naturaleza polifónica de la propia vida». Pero el rasgo descubierto en la obra de Dostoievski, al igual que ocurre con otros, sirve pronto para caracterizar no sólo el conjunto de su narrativa, sino también, aunque de manera indirecta, toda una tendencia de la novela europea por la que Bajtín, además, apenas ocultará su preferencia.

El relativismo de carácter dialógico profesado por Bajtín, pese a diferencias sustanciales e inevitables, se aproxima así a concepciones sobre la novela moderna como la de Sartre (Todorov, 1991: 76-77). El diálogo no puede ser concluido o cerrado puesto que, al contrario de lo que ocurre en la dialéctica, el diálogo no conduce a una síntesis superadora de diferencias. Los puntos de vista múltiples no reducen sus distancias entre sí, no son asimilados: de ahí que el diálogo —en cuanto a su desarrollo conceptual - no pueda cerrarse, toda vez que no hay un fin o una culminación. El diálogo se trunca (véase un ejemplo de ello en Apuntes del subsuelo $)^{5}$ o no es diálogo.

3. El propio Bajtín se ocupa de presentar testimonios del escritor que contradicen de alguna forma precisamente aquello que el investigador está afirmando sobre la obra de aquél. El primer obstáculo que esquiva -más que supera- Bajtín es la idea dominante o reinante (vladychestvuiushaia ideia) a la que se refiere Dostoievski en relación con sus obras: una idea dominante cuyo significado Bajtín reduce a la manera de disponer el material en la obra y que en ningún caso desea identificar con un punto de vista, una idea de fondo a la que se subordinen todos los demás elementos de la obra. Más evidente aún es

4 TODOROv, 1991: 75. Parece, por otro lado, perfectamente lícito identificar las "voces" de Bajtín con los puntos de vista (individuales) discursivos, tal y como hace Borís A. Uspenski en su Poética de la composición (USPENSK1, 1970), donde el polifonismo se equipara, dentro de unas coordenadas téricas sensiblemente distintas, a la multiplicidad de puntos de vista en la obra.

${ }^{5}$ La palabra del hombre del subsuelo es una palabra contradictoria, internamente dialogizada hasta límites extremos, como pone de manifiesto Bajtín en el segundo capitulo de la segunda parte de los Problemas de la obra de Dostoievski (1929). «El hombre del subsuelo mantiene idéntico diálogo sin solución tanto consigo mismo como con el otro» (BAJTiN, 1994: 138). La tendencia a la inconclusión, la ausencia de término en el diálogo explican el final de los Apuntes del subsuelo, en el que el narrador retoma su voz propia para truncar de forma expeditiva un discurso que, como se indica explícitamente, no acaba ahf (DosTotevskI, 1989: 550). 
la contradicción entre una de las premisas, acaso la fundamental, de la polifonía —concepto, resaltemos, creado por Bajtín— y el siguiente testimonio de Dostoievski:

Nos parece que no basta en absoluto con exponer de manera verdadera todos los rasgos del personaje; hay que aclararlo decididamente con el propio punto de vista artístico. A ninguin precio el verdadero artista debe mantenerse en situación de igualdad con el personaje representado, contentándose con la sola verdad de ese último: no se alcanzará de esa manera una verdad en la impresión (en Polnoe sobranie sochinenii [XXI, Moscú, 1980, p. 97], citado por Todorov, 1991: 79).

El pasaje golpea sobre uno de los pilares tal vez más importantes de la polifonía: la igualdad entre autor y personaje, entre las voces que representan. La segunda oración de Dostoievski (hay que aclararlo decididamente con el propio punto de vista) choca con otra de las explicaciones preferidas por Bajtín: la autoconciencia del personaje es contrastada con la opinión que otros personajes manifiestan sobre él, proceso en el que no toma parte alguna la voz del autor, que nunca habla sobre el personaje - lo que implicaría una posición de privilegio-, sino, en todo caso, con él (Bajtín, 1994: 57). Todorov, quien exprime al máximo estas - y algunas otras- - contradicciones, mantiene la esencial desigualdad entre autor y personaje, diferencia que se trasluce de forma implícita en algunos de los propios enunciados bajtinianos: «el autor no es más que un participante en el diálogo (y su organizador)». Si el autor es, además de voz participante, el organizador del diálogo, parece claro que no es posible hablar de igualdad. El autor es quien crea la obra, y en ella idea las voces de todos sus personajes, al tiempo que establece las relaciones que las oponen entre sí. Pero la evidencia de estas características no podía escapársele a Bajtín. Todorov juega aquí de forma un tanto malévola (por reduccionista en exceso), ya que la situación de igualdad que Bajtín propugna no es precisamente la que de ninguna manera puede existir entre la natura non creata et creans (autor) y la natura creata (personaje), sino la que el propio autor define entre el papel que él mismo se asigna en la obra en tanto voz del autor y las voces autonomas, plenas, que confiere a los personajes. Para decirlo de otra manera, Dostoievski no es menos autor (real o «autor de la imagen del autor», como dirá Bajtín en otro momento) que Tolstói ${ }^{6}$, lo que varía - en la novela organizada de forma dia-

- La distinción se establece entre las categorías de autor-creador e imagen del autor en la obra. Es sólo a esta última a la que se pueden aplicar los criterios de dialogismo y polifonía. Hablar de igualdad de planos con referencia a los personajes y al autor-creador no tiene, evidentemente, 
lógica- son las relaciones entre la posición en la obra de la conciencia del autor y las de los personajes, consecuencia, en última instancia, de una concepción del mundo distinta ${ }^{7}$. En la segunda edición del Dostoievski (1963) Bajtín señala: «La posición del autor con respecto al héroe en la novela polifónica de Dostoievski es una posición consecuentemente realizada y llevada hasta sus últimos extremos, la cual afirma la autonomía, la libertad interna y el carácter inconcluso y no definitivo del héroe» (Bajtín, 1994: 270). No obstante, el pie de igualdad entre autor y personaje observado (o propugnado) por Bajtín ha sido sutilmente criticado desde el interior de la propia teoría bajtiniana por $\mathrm{A}$. $\mathbf{N}$. Jots (1991: 22-38), quien detecta una seria contradicción entre los presupuestos de la polifonía y la naturaleza divergente de las relaciones entre el discurso propio y el ajeno en la voz del autor y en la de los personajes. El autor en Dostoievski integra libremente en su discurso la palabra ajena (incluyendo la de los personajes), pero el héroe es en cierto modo «sordo» a la palabra del autor, su conciencia no incluye la presencia del autor ni de su actividad valorativa. Para Jots, esta diferencia impide tratar como iguales - desde el punto de vista de la organización del discurso y de la autoconciencia- a funciones estructurales de la obra localizadas en niveles esencialmente diversos. En contraste, las afirmaciones que encabezan la primera (pero también la segunda) redacción del Dostoievski insisten en la idea que vertebra la noción de la polifonía ( $y$, al mismo tiempo, la del dialogismo):

En sus obras aparece un tipo de personaje cuya voz está construida de la misma forma en que se construye la voz del propio autor en la novela común. La palabra del héroe acerca de sí mismo y sobre el mundo es tan válida y tan plenamente significante como la palabra común del autor: no se halla supeditada a la imagen objetiva del personaje en tanto una de sus características, pero tampoco sirve de portavoz de la palabra del autor. Posee una excepcional autonomía en la estructura de la obra, suena como si estuviera al lado de la palabra del autor y de forma especifica se combina con ésta y con las voces igualmente válidas de otros personajes (Bajtín, 1994: 14).

sentido (cfr. HerRero Cecilia, 1992: 62). En cuanto se refiere al proverbial monologismo de Tolstói, es necesario mencionar, como hizo TODOROV (1981: 99-100), las vacilaciones que experimentó al respecto la posición de Bajtín. Si en la segunda edición del Dostoievski (1963) refuerza su idea de que kel mundo de Tolstói es monoliticamente monologico (...); no aparece, en su mundo, una segunda palabra válida (al lado de la del autor)», anteriormente, en «La palabra en la novela» (193435), habia indicado que en Tolst6i kel discurso se distingue por un neto dialogismo interior».

1 Para una explicación sociológica del origen de la multiplicidad polifónica vid. M. PIERRETTE MALCUZINSKI, 1984: 45-56. Vease, además, en general, acerca de la representación del plurilinglismo social en la literatura, BATTN, 1989: 225-229. 
En cualquier caso, la discusión -incluidas las divergencias entre las intenciones creadoras de Dostoievski y las conclusiones teoricas que Bajtín extrae de los resultados literarios- desvela un rasgo no demasiado oculto de la labor de este último: el Dostoievski que estudia y al que atribuye gran cantidad de particularidades novedosas (entre ellas, la ausencia y la imposibilidad de una verdad impuesta, absoluta y única, factor fundamental en el dialogismo) es un Dostoievski en buena medida bajtinizado, traspasado de la visión literaria de su investigador y adecuado, en fin, a las exigencias de una teoría incipiente en busca de corroboración a través de realizaciones concretas y analizables: Dostoievski en Bajtín es el Dostoievski de Bajtín.

4. El paso de la novela polifónica de Dostoievski al plurivocalismo en tanto rasgo constitutivo de géneros secundarios como la novela ${ }^{8}$ requiere de la desviación previa de la atención analítica hacia la tipología de los discursos (y de sus formas de presentación). A partir de «La palabra en la novela» la obra será, antes que construcción o arquitectónica, «heterología, pluralismo de voces, reminiscencia y anticipación de los discursos pasados y futuros» ${ }^{9}$. En el estudio titulado «De la prehistoria de la palabra novelesca» (1940) se investigan los antecedentes de la creciente incrustación plurivocal, plurilingüe y dialógica (a partir de géneros como la parodia, «que desmonta los ritos y las imágenes monoestilísticas de cuanto se convierte en estático y se erige en autoridad», vid. Zavala, 1991: 67) en el discurso monológicamente homogéneo de las obras antiguas y medievales. La idea de una oposición permanente entre una tendencia monológica y otra dialógica en la evolución de la novela europea, que aparece ya en el primer Dostoievski (1929), pasa principalmente por dos etapas de desarrollo teórico. La primera imagen de esta oposición corresponde a una separación tajante entre monologismo y dialogismo (y plurivocalismo), que subraya la radical novedad de la obra de Dostoievski en el panorama de la literatura europea: Bajtín lo presenta como el creador de la novela polifónica, «un género novelesco completamente nuevo. Por ello su obra no entra en ninguna clasificación, no se subordina a ninguno de los esquemas histórico-literarios que estamos acostumbrados a aplicar a los fenómenos de la novela europea» (Bajtín, 1994: 14). El ensayo «La palabra en la novela» supo-

8 Secundarios por la complejidad de su estructura interna, basada en la interacción c interpenetración de los géneros discursivos primarios, cfr. «El problema de los géneros discursivos» (1952-1953), en BAJTí, 1979: 239, y, en la versión espaniola, BAJTí, 1982: 261-262.

9 TODOROV, 1991: 84. Recordemos la definición del género que proporciona el estudio *La palabra en la novela»: «La novela como todo es un fenomeno pluriestilístico, plurilingual y plurivocal» (BATTIN, 1989: 80, trad. de Helena S. Kriúkova y Vicente Cazcarra). Véanse asimismo las continuas referencias al plurifonismo individual presente en la novela. 
ne una evolución también en este aspecto de la teoría bajtiniana, puesto que atenúa en gran medida el rigorismo de tal separación, afirmando la posibilidad de la interacción entre ambos tipos de macrodiscurso, una nueva comprensión histórica y dinámica que reconoce puntos de transición entre las conciencias lingüísticas ptolomeica y galileica ${ }^{10}$ que determinan, a juicio de Bajtín, el predominio de una u otra tendencia discursiva. A diferencia de la corriente dialógica, que en su desarrollo no sufre trastorno estructural alguno, la línea monológica correspondiente a la conciencia ptolomeica experimenta una evolución que la aproxima paulatinamente a la pluralidad discursiva característica desde un principio de los géneros dialógicos. La identificación de estas dos líneas de evolución de la novela europea, entre las que se reconoce la posibilidad de la convergencia ", va a conducir a Bajtín a la profundización del análisis de la tendencia dialógica en busca de precedentes de la novela polifónica de Dostoievski. Esta búsqueda, explícita ya en «Epopeya y novela» (1941), constituye en cierta manera el núcleo del capítulo cuarto de los Problemas de la poética de Dostoievski (1963), que indaga en algunas de las sucesiones histórico-literarias descubiertas en el tratado anterior. Géneros decididamente dialogizados como el diálogo socrático y la sátira menipea, pertenecientes ambos al dominio de lo «serio-cómico» en la literatura, preparan el terreno en el que se han de desenvolver «las variantes tardías más importantes de la novela europea» («Epopeya y novela», cfr. Bajtín, 1989: 467), entre ellas, claro es, la novela de Dostoievski. El rasgo previo que más profundamente une la actividad estética plasmada en la literatura de lo «serio-cómico» y la de la novela es el punto de partida de su objeto de representación. La zona de contacto inmediata (familiar y polémica, consecuencia de la carnavalización de estos géneros) con la realidad contemporánea, con el presente inestable y efímero, establece los lazos de unión entre, por ejemplo, la sátira menipea (de la que en Dostoievski se encuentran dos ilustraciones: los cuentos «fantásticos» Bobok [El haba], de 1873 y Son smeshnogo cheloveka [El sueño de un hombre ridículo], de 1877) y la novela moderna. La incursión del carnaval en la literatura (de la que Don Quijote será, a juicio de Bajtín, un buen ejemplo) supone el inicio de la descentra-

${ }^{10}$ Mientras que la conciencia lingústica ptolomeica se relaciona con una concepción integradora, unitaria, de la diversidad linguística, lo que implica que los discursos elaborados desde esta visión se orientan hacia la unidad estilística, la conciencia galileica hace referencia -en lo que ahora nos importa - a la aceptación artística de la pluralidad, en consonancia con las tendencias descentralizadoras, centrffugas, de la vida del lenguaje o del «universo ideológico verbal» (BAJTiN, 1989: 88).

"Como señala Tatiana Bubnova (1980: 110), ken lugar de dos corrientes novelísticas aisladas, hay dos desarrollos opuestos que finalmente convergen*. 
lización ideológica de la obra, al contraponer al discurso literario uniforme (monológico) consagrado por la tradición «elevada» el conjunto de los diversos discursos sociales, introducidos en la obra por medio de las distintas voces ideológicas presentes en ella. La obra carnavalizada revela una estructura de ambivalencias que alcanza cada uno de sus niveles de composición (de ahí su profundo dialogismo). Bajtín (1994: 388-194) se encarga de mostrar el fundamento y las derivaciones de esa misma estructura en novelas como El idiota, Los demonios o Los hermanos Karamazov.

La edición definitiva del Dostoievski asiste, por otro lado, a la presentación de una nueva división, esta vez en tres líneas - aunque con numerosas formas intermedias-, del desarrollo de la novela europea: la épica, la retórica, y la del carnaval, siendo esta última la que anticipa algunas de las particularidades que van a definir la novela de Dostoievski en tanto producto de esa línea de evolución ${ }^{12}$.

5. Las raíces más remotas de la polifonía dostoievskiana se hallan, por lo tanto, en la literatura antigua dialogicamente opuesta a los géneros elevados (entre éstos, por ejemplo, la epopeya o la tragedia). El diálogo socrático y la sátira menipea, en calidad de representantes de la tendencia discursiva carnavalizada, constituyen los primeros eslabones de una cadena que lleva hasta Dostoievski a través de la novela picaresca, de Rabelais, de Cervantes, y de Gógol ${ }^{13}$. La obra de Dostoievski se instala así, al contrario de lo que ocurría en la primera edición del estudio, en toda una tradición novelística europea de la que no es sino una variante, todo lo trascendental y original que se quiera, pero en ningún caso un género nuevo sin parangón en la historia de la narrativa. Esta visión renovada del lugar de Dostoievski en la literatura contrasta singularmente con las definiciones proclamadas en la redacción de 1929. Desde esta perspectiva, resulta en verdad interesante la comparación de las secciones «Conclusion» de ambas ediciones. Al tiempo que en 1929, tras afirmar en las primeras páginas la absoluta singularidad de la novela de Dostoievski (vid. supra, Bajtín, 1994: 14), Bajtín le aplica definitivamente el término «polifónica» -aunque su contenido sólo levemente podría deslindarse del de dialogismo o incluso del de «gran diálogo» que en ocasiones Bajtín atribuye al conjunto de la novela-, entre las conclusiones de 1963 destaca ya la relativizacion del papel innovador de la novela polifónica de Dostoievski, esencialmente continua-

12 Vid. BATTIN, 1994: 317. Estas corrientes evolutivas de la novela europea se identifican por el predominio de uno u otro de los componentes (épico, retórico o carnavalesco) que constituyen juntos, según Bajtín, las raíces fundamentales del género novelístico.

13 Cfr. la interpretación de Almas muertas como sátira menipea en «Épica y novela» (BATTIN, 1989: 472-473). 
dora de «la línea dialógica en el desarrollo de la prosa artística europea» (Bajtín, 1994: 490). Dostoievski no es ya el creador de un nuevo género novelesco, sino el autor de una variedad genérica de la novela dialógica ${ }^{14}$. En opinión de este segundo Bajtín, es posible hablar de una especie de reflexión artística polifónica, fenómeno que excede claramente los límites exclusivos del género de la novela, y dentro de éste, de la novela de Dostoievski. La reflexión polifónica es la única capaz, a diferencia de la monológica, de trasladar a la obra «la conciencia humana pensante y la esfera dialogica de su ser» (ibidem). Como habia dicho anteriormente, en «Para una reelaboración del libro sobre Dostoievski», la unidad del mundo einsteniano (leamos dialógico) es más compleja y profunda que la unidad del mundo de Newton (monológico). Dostoievski crea, de esta manera, «un modelo artístico del mundo mucho más complejo» que el representado en las obras monologicas, concluye el Bajtín de 1963. Pero de nuevo nos hallamos frente al problema del alcance de la creación dostoievskiana. ¿Acaso la línea dialógica de desarrollo de la prosa europea anterior a Dostoievski no representaba ya un mundo más complejo? ¿En qué reside la aportación de Dostoievski, o dicho de otra forma, cuál es la diferencia entre dialogismo y polifonía, si ésta es algo más que un diálogo múltiple entre conciencias autónomas? Pues la oposición bajtiniana esencial sigue siendo, según todos los indicios, la que se establece entre monologismo y dialogismo (de la que el plurivocalismo conducente a la polifonía no serfa sino una definición más detallada, encaminada tal vez a la forma de presentación del discurso y no al principio de su estructuración) ${ }^{15}$. El método polifónico aparece entonces como la manifestación artística plural del diálogo abierto e inconcluso entre sujetos, conciencias activas no subordinadas a una autoridad filos6fica o moral, encarnada en la palabra del autor o en la de uno de los personajes (ausencia de verdad absoluta). Pero en la definición, como se ve, no hay nada que no contenga el propio principio dialógico ${ }^{16}$. De hecho, se ha podido afirmar que el

14 No deja de sorprender, en cualquier caso, cierto descuido en la revisión del texto de 1929 , ya que, si bien las conclusiones de la segunda edición parecen en gran medida contrapuestas a las primeras - sobre todo en lo que atanfe al cardcter de la originalidad de la obra dostoievskiana-, no se entiende la conservación de fragmentos como los citados en el punto 4 del presente trabajo (cfr. BATTIN, 1994: 209).

15 Ciertas definiciones bajtinianas de la construcción polifónica de la obra no hacen sino acentuar la proximidad (o identidad) entre polifonía y dialogismo: «cada elemento de la obra se ve situado inevitablemente en un punto de intersección de voces, en la zona de contacto de dos réplicas encontradas» (BATTiN, 1994: 179).

${ }^{16}$ En *Para una reelaboracion del libro sobre Dostoievski* el dialogismo que caracteriza la novela de Dostoievski se define como kuna forma particular de interacción de conciencias igualmente válidas y equipolentes» (BNTtN, 1979: 309). La definición bien pudiera valer a su vez para la noción bajtiniana de la polifonfa. 
concepto bajtiniano del dialogismo novelesco no es sino la abstracción, la idealización térica derivada del polifonismo -entendido como diversidad estética_ de la novela de Dostoievski (Bibler, 1991: 99). De este modo, la diferencia conceptual entre dialogismo y polifonía (o polílogo, si empleamos el término de la estilística actual) no acaba de mostrar, pese a Bajtín, contornos demasiado precisos. Así, si se han podido aplicar a la narrativa en general términos como «dialógica» o «polifónica» de manera indiferenciada (Zavala, 1991: 82), ello es en gran medida debido a la ausencia de una delimitación decisiva de los significados de una y otra palabra, o lo que es lo mismo, a su sinonimia en la práctica. Tal vez sea ésta la razón que ha hecho posible el que posteriormente se haya extendido el concepto de la polifonía (al igual que el de dialogismo) a toda la novela moderna o incluso al propio genero novelesco ${ }^{17}$, algo que Bajtín (al menos en las páginas del Dostoievski) no hace en ninguna ocasión - sí, en cambio, en determinados momentos, con términos como la heteroglosia (raznoiazychie) o el plurivocalismo (mnogogolosost') -, pero a lo que da pie en la conclusión del segundo Dostoievski, donde introduce la idea de un tipo de reflexión artística polifónica (que guía materializaciones concretas como las de Dostoievski), a la vez que enjuicia la influencia de la novela polifónica en el desarrollo subsiguiente de la novela europea. Por otro lado, en unos apuntes que preceden cronológicamente a esa segunda edición — «El pro-

17 Cfr. en la solapa de la edición española Teoría y estética de la novela (1989): «el carácter esencialmente dialógico y polifónico del género novelístico». En M. DEL CARMEN BOBES NAVES (1993, en todo el cap. I) se puede encontrar una de tantas ilustraciones de esta generalización de la polifonía a todo el discurso novelesco, lo que entrafia primeramente, como puede observarse, una ampliación del propio concepto de polifonía a los ámbitos delimitados por Bajtín para los hechos de plurilinglismo (o heteroglosia) y de heterologia (diversidad de generos), de los que se deriva la interdiscursividad narrativa y que conforman, junto con la plurivocidad, el cosmos múltiple y abierto del genero actual de la novela. Iris M. Zavala (1991: 82) afirma, extendiendo el ámbito de la polifonía a toda manifestación lingústica: knuestro propio lenguaje y nuestra propia lengua son polifónicas... La polifonfa radica en nuestro propio mundo comunicativo; el lenguaje es por naturaleza polifónico y dialógico, porque el otro, lo otro forma parte sustancial del acto comunicativo siempre». (BATIN (1994: 276) también dirá que la propia vida es de naturaleza polifónica, con lo que acentúa de nuevo la similitud conceptual entre polifonía y dialogismo). Pero la polifonía, en tanto término que se refiere a la manifestación particular del dialogismo en la novela dostoievskiana, se cińe en principio al conflicto e interacción de las voces (vehículos de ideas encamadas en los personajes y en el autor) presentes en estructuras narrativas que les confieren plena autonomía y que, además, no privilegian a ninguna de ellas sobre las otras (de lo contrario, no habría diálogo). Cfr. WALL, 1984: 69-73: «La polyphonie romanesque se caracterise surtout par des voix 'equipollentes' et multiples... Mais elle exige aussi, comme c'est le cas pour la musique, qu'il n'y ait aucune voix, que ce soit celle d'un personnage, du narrateur ou du lecteur, qui soit privilégice par rapport aux autres». Incluso, en la visión un tanto reductora de MICHAEL HOLQUIST (1994: 108), «such categories as 'Bakhtinian carnival' or 'polyphony' come to mean no more than a liberating licentiousness in the first case and no more than multiple point of view in the otherm. 
blema del texto en linguiística, filología y otras ciencias humanas» (19591961) - Bajtín (1979: 291) indicará que después de Dostoievski «la polifonía irrumpe vigorosamente en toda la literatura mundial», aunque la generalización del término no va más allá ni afecta a los antecesores de la novela polifónica (desde los autores de diálogos socráticos y sátiras menipeas hasta Rabelais, Cervantes, Swift, Voltaire o Hugo), cuyas obras, por su carácter dialógico, carnavalizado, iluminan las raíces de la polifonía, pero se hallan aún desprovistas de ella (Bajtín, 1994: 331, 394) ${ }^{18}$. Para tratar de diferenciar la obra de Dostoievski de la de sus predecesores, Bajtín introduce, además, un matiz que no deja de resultar extraño: llama al autor de Los hermanos Karamazov el creador de «la auténtica polifonía», lo que parece sugerir que algo de ella habría (aunque no fuera más que una variante espuria, a medio camino aún entre la homofonía y la polifonía) en la obra de escritores anteriores. A partir de una concepción laxa de la polifonía (en tanto mera diversidad de voces en la novela) resulta, además, comprensible la observación de $\mathbf{R}$. Wellek (1980, citado por Pomorska, 1984: 173), según la cual el fenómeno "polifónico» había sido ya estudiado y admitido en la crítica literaria tradicional. Pero no es ahí, en todo caso, donde reside el conflicto entre las dos nociones bajtinianas y entre las manifestaciones artísticas que supuestamente sustentan y justifican la diferencia. La resolución del problema tiende más bien hacia la disolución de la aparente dualidad dialogismo-polifonía y, al mismo tiempo, a la atenuación del carácter innovador de la novela de Dostoievski. Refiriéndose a la relación entre ésta y la menipea, Bajtín anota:

En realidad, hallaremos todas las particularidades de la menipea (por supuesto, con las correspondientes transformaciones y complicaciones) en Dostoievski. De hecho, se trata de un mismo universo generico, pero en la menipea éste nos es dado en el inicio de su desarrollo, mientras que Dostoievski representa su culminación (Bajtín, 1994: 330).

En este contexto de evolución y de renovación estética, exento de ruptura, Dostoievski, por otra parte, aplica de forma original en sus obras una es-

18 JULIA KRISTEVA (1969: 152) pasa por alto esta separación y considera que «le roman qui englobe la structure camavalesque est appelé roman polyphoniquew. Por ello, para Kristeva, tanto Rabelais como Swift -o, en época contemporánea, Proust, Joyce o Kafka- son autores de novelas polifónicas en la misma medida en que lo es Dostoievski. Aunque parece evidente que no es éste el pensamiento original de Bajtin, no cabe duda de que las conclusiones de Kristeva tienen mucho que ver con la virtual similitud de significado que une --desde la perspectiva del discurso narrativo- la polifonia y el dialogismo, siendo tanto una como otro (si aún es posible deslindarlos) efectos más o menos directos de la carnavalización de la literatura. 
tructura artística completamente dialogizada (polifónica en virtud de la manifestación plural del diálogo), con multitud de conciencias autónomas y no fundidas, enfrentadas entre sí sin solución (la sincrisis de los diálogos socráticos), al género de aventuras (Bajtín, 1994: 371), modificado sensiblemente en el sentido de que los únicos acontecimientos que tienen lugar son los sucesos de la conciencia, de la lucha de ideas que ya Engelhardt había identificado como núcleo fundamental de la novela de Dostoievski ${ }^{19}$. Y es esta misma característica de su obra la que puede condicionar que el dialogismo, a ojos de Bajtín, alcance precisamente en Dostoievski su forma suprema, la polifonía ${ }^{20}$, puesto que la atención creadora se encuentra centrada -como hasta entonces no lo había estado- en la contraposición mutua de diversas conciencias independientes, así como en los mecanismos que posibilitan una fiel traslación al lenguaje artístico de la diversidad (siempre plural y compleja) de la existencia.

6. Las generalizaciones y extensiones de términos como el dialogismo (consideremos también la polifonía) a toda la novela en tanto género literario en modo alguno ocultan su origen como definiciones de la obra de Dostoievski. No parece excesivamente arriesgado afirmar que Bajtín halla primero las características dialógicas (o polifónicas) de la novela dostoievskiana -en una búsqueda, por lo demás, no exenta de expectativas téricas previas ( «toda observación está imbuida de teoría», diría K. Popper)- para después ampliar el ámbito de su peculiaridad, de forma más o menos directa dependiendo de cada rasgo, a toda una tendencia de la prosa literaria europea. En ese proceso de ampliación (que va de la primera a la segunda edición del Dostoievski, pasando por el eslabón clave que constituye el ensayo «Slovo $v$ romane» [ $\ll$ La palabra $\longrightarrow$ el discurso - en la novela»]), resulta lógica cierta reducción del carácter innovador de la obra de Dostoievski que había asombrado en un principio a Bajtín. Las razones de esta modificación proceden en gran parte de la nueva perspectiva histórica, capaz de trazar vínculos evolutivos entre formas narrativas aparentemente aisladas, adoptada por el investigador. La polifonía de la novela de Dostoievski - de llevar hasta sus últimas consecuencias esta visión renovada - intensifica las particularidades dialogicas de la prosa carnavalizada y añade tal vez el relativismo, la indeterminación ideológica, frutos

19 Los elementos argumentales actúan de motivos funcionales necesarios para alcanzar el estado crítico de la relación entre conciencias que posibilita el auténtico diálogo. En Dostoievski ese instante crítico que incita al diálogo, a la revelación (anacrisis) halla su correlato espaciotemporal en el cronotopo del umbral ( $\alpha$ Las formas del tiempo y del cronotopo en la novela», BAJTN, 1989: 399).

20 «En el dialogismo (resp. la subjetividad de sus personajes) Dostoievski atraviesa cierto Kmite, su dialogismo adquiere un calidad nueva (superior)» (BATTIN, 1979: 291). 
del conflicto permanente e irreductible de perspectivas confrontadas, en el contexto de la obra, pero su esencia no es otra que la del principio dialógico bajtiniano ${ }^{21}$. Situada en el centro de la visión bajtiniana de Dostoievski, la polifonía es, además, el reflejo literario de una conciencia lingüística y de una visión del mundo que aceptan e integran en su reflexión artística la pluralidad (estilística, linguiística, social) de la cultura humana, una conciencia que por algo Bajtín denomina «galileica» y que, a fin de cuentas, no es exclusiva del discurso de Dostoievski. Las raíces de la polifonía se vinculan así a la esencia dialogica del ser («ser significa comunicarse», Bajtín, 1994: 187), y por ello sus límites son los límites del gran diálogo entre sujetos.

\section{REFERENCIAS Bibliograficas}

BATTN, MuAth (1979): Estetika slovesnogo tvorchestva, Moskva, Iskusstvo.

BAJTtN, MuAt (1982): Estética de la creación verbal, México, Siglo XXI.

Bajtin, Muafl (1989): Teoría y estética de la novela, Madrid, Taurus.

Basttr, Muatl (1994): Problemy tvorchestva Dostoievskogo. Problemy poetiki Dostoievskogo, Kiev, Next.

Btbler, Vladimir S. (1991): Mijail Mijailovich Bajtin ili Poetika Kul'tury [M. M. Bajtín o la poética de la cultura], Moskva, Progress.

Bobes Naves, MARfa del CARMen (1993): La novela, Madrid, Sintesis.

Bubnova, Tatiana (1980): «El espacio de Mijail Bajtín: filosofía del lenguaje, filosofia de la novela», Nueva Revista de Filologia Española, XXIX-I, 87114.

DOSTOIEVSKI, FIODOR M. (1989): Sobranie sochinenii v piatnadtsati tomaj, Leningrad, Nauka, tomo IV.

ENGELHARDT, BoRIs M. (1924): «Ideologicheskii roman Dostoievskogo» [«La novela ideológica de Dostoievski»], Dostoievskii: statii i materialy, Moskva-Leningrad, Mysl'.

Grossman, L. P. (1925): Poetika Dostoievskogo, Moskva.

HerRERO CECHIA, JUAN (1992): «Mijail Bajtín y el principio dialógico en la creación literaria y en el discurso humano», Suplementos Anthropos, 32, 55-66.

HolquIST, Michael (1994): Dialogism. Bakhtin and his World, 24 reimpr., London/New York, Routledge.

21 *Todo en las novelas de Dostoievski tiende al diálogo, a la contraposición dialógica, como a su mismo centro. Todo lo demás son medios, en tanto que el diálogo es el fin. Una sola voz no concluye ni resuelve nada. Dos voces, ése es el mínimo de vida, el mínimo de existencia» (BAJTIN, 1994: 161 y 473.) 
JoTs, A. N. (1991): «Predely avtorskoi otsenochnoi aktivnosti v polifonicheskom 'samosoznanii' geroia Dostoievskogo» [ «Lf́mites de la actividad valorativa del autor en la 'autoconciencia' polifónica del héroe de Dostoievski»], Dostoievskii. Materialy $i$ issledovania, Leningrad, Nauka, 22-38.

KrISTEVA, Julia (1969): «Le mot, le dialogue et le roman», Semeiotiké. Recherches pour une sémanalyse, Paris, Seuil, 143-173.

LOTMAN, IURI M. (1992): «Tekst i poliglotism Kul'tury» [«El texto y el poliglotismo de la cultura»], Izbrannye statii, Tallinn, Aleksandra, 3 vols., I, 142-147.

MALCUZYNSKI, MARIE PIERRETTE (1984): «Critique de la (dé)raison polyphonique», Études Françaises, 20/1, 45-56.

POMORSKA, KRYSTINA (1984): «Mixail Baxtin and his dialogic universe», Semiotica, 48-1/2, 169-174.

Todorov, Tzvetan (1979): «Bakhtine et l'alterite», Poétique, 40, 502-513.

TODOROv, Tzvetan (1981): Mikhail Bakhtine. Le principe dialogique, Paris, Seuil.

Todorov, Tzvetan (1991): Crítica de la crítica, Barcelona, Paidós.

UsPensKu, Borfs A. (1970): Poetika kompozitsii [Poética de la composición], Moskva.

WALL, ANTHONY (1984): «Apprendre à écouter: le problème des métaphores musicales dans la critique bakhtinienne», Etudes Françaises, 20/1, 65-74.

WeLleK, RENE (1980): «Bakhtin's view of Dostoevsky: Polyphony and camivalesque», Dostoevsky Studies, I, 130-140

ZAVALA, IRIS M. (1991): «Dialogía, voces, enunciados: Bajtín y su círculo», La posmodernidad y Mijall Bajtín. Una poética dialógica, Madrid, Espasa-Calpe, 37-98. 